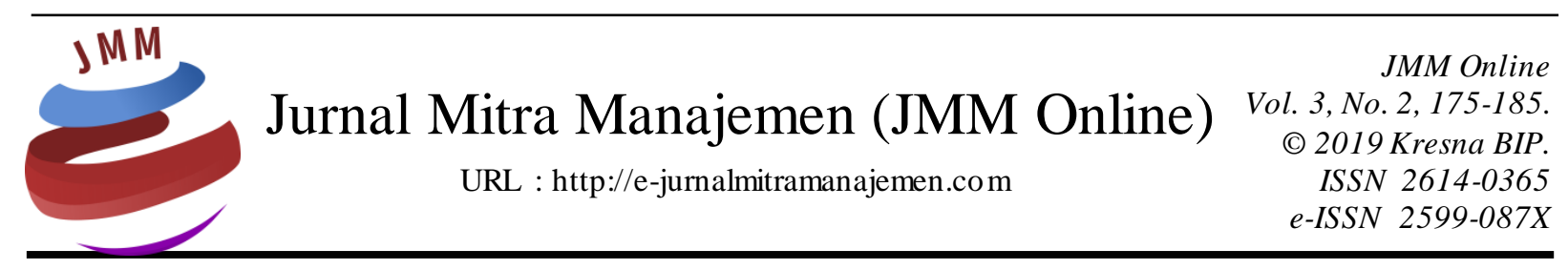

\title{
EVALUASI PEMBELAJARAN KEWIRAUSAHAAN DI PERGURUAN TINGGI (STUDI PADA MAHASISWA PROGRAM STUDI MBTI ANGKATAN 2015 UNIVERSITAS TELKOM)
}

\author{
Dhea Alyani 1), Astri Ghina 2) \\ Universitas Telkom
}

INFORMASI ARTIKEL

Dikirim : 07 Februari 2019

Revisi pertama : 11 Februari 2019

Diterima : 13 Februari 2019

Tersedia online : 04 Maret 2019

Kata Kunci : Pendidikan

Kewirausahaan, Pembelajaran

Kewirausahaan, Kompetensi

Kewirausahaan, Analisis kesenjangan

Email :dhealyaaa@gmail.com ${ }^{1)}$, aghina@telkomuniversity.ac.id ${ }^{2)}$
ABSTRAK

Tujuan dari penelitian ini untuk melihat tingkat kesenjangan harapan mahasiswa dengan persepsi mahasiswa terhadap pelaksanaan kurikulum kewirausahaan yang berdampak pada pengukuran kompetensi wirausaha mahasiswa MBTI 2015 yang sudah menyelesaikan proses pembelajaran kewirausahaan. Hasil dari penelitian akan menjadi umpan balik untuk prodi MBTI. Metode pengumpulan data dalam penelitian ini dengan melakukan penyebaran kuesioner terhadap 231 mahasiswa/responden. Kuesioneryang digunakan memiliki beberapa pernyataan dengan skala likert 7 titik. Teknik pada penelitian ini adalah teknik non-probability dengan convience sampling. Hasil penelitian ini menyatakan berdasarkan analisis deskriptif, kompetensi wirausaha mahasiswa setelah mengikuti pembelajaran pendidikan kewirausahaan berada dalam kategori tinggi, yaitu sebesar $78 \%$, ini menunjukan bahwa mahasiswa setuju memiliki kompetensi tersebut walapun terjadi kesenjangan pada kurikulumpendidikan kewirausahaan yaitu sebesar -0,370. Setiap dimensi rencana pembelajaran mata kuliah memiliki gap yang negatifkarena nilai harapan berada diatas nilai persepsi pelanggan. Melalui hasil penelitian ini dapat disimpulkan bahwa program studi MBTI harus membenahi kinerjanya agar meminimalisir kesenjangan antara harapan dan persepsi. 


\section{PENDAHULUAN \\ Latar Belakang}

Masalah universal yang dihadapi oleh hampir semua Negara adalah masalah pengangguran, dan hal ini memang harus segera ditanggapi secara serius (Candra, 2017). Tingkat pengangguran di Indonesia sendiri menempati posisi ke-3 tertinggi di Asia Tenggara dengan angka 5,13 pada tahun 2018 (Trading Economics, 2018). Dampaknya penciptaan lapangan kerja baru sangat diperlukan, karena apabila tidak adanya lapangan kerja baru, jumlah pengangguran akan semakin meningkat. David Mc.Clelland (dalam Kuswara, 2012) menyatakan suatu Negara dapat dikatakan maju apabila $2 \%$ dari populasinya adalah wirausaha, karena seorang wirausaha memiliki peran penting bagi kemajuan ekonomi negara dan membantu mengurangi tingkat pengangguran Negaranya.

Potensi sukses seorang wirausaha adalah mereka yang ingin belajar memahami pentingnya pendidikan untuk meningkatkan pengetahuan dan menjadikan keilmuan atau teori sebagai landasan berpikir yang tujuannya untuk memahami suatu masalah. Kurikulum pendidikan kewirausahaan di perguruan tinggi hendaknya dapat menghasilkan wirausaha yang lebih berkompetensi tinggi, hal ini dapat terjadi apabila dilakukannya pembenahan pada silabus mata kuliah kewirausahaan, meliputi metode, materi dan strategi pembelajaran untuk menarik minat mahasiswa untuk berwirausaha (Purwana dan Wibowo, 2017:46). Penelitian ini dilakukan untuk mengetahui seberapa besar kesenjangan antara harapan mahasiswa sesuai tujuan pembelajaran dengan persepsi mahasiswa terhadap pelaksanaan proses pembelajaran kewirausahaan di MBTI 2015 dan untuk mengetahui seberapa tinggi tingkat kompetensi berwirausaha dari mahasiswa MBTI 2015 yang telah menyelesaikan proses pembelajaran kewirausahaan. Universitas Telkom menjadi salah satu perguruan tinggi swasta yang menempatkan entrepreneur sebagai bagian yang tak terpisahkan dari suatu proses pendidikan, selain itu untuk memenuhi Rencana Induk Pengembangan (RENIP) Telkom University yang merupakan Grand Strategy Telkom University di 25 tahun yang akan datang dengan visi di tahun 2038 yaitu "Menjadi Sebuah Universitas Entrepreneur Global (Global Entrepreneurial University). Dari ke 7 Fakultas yang ada, penelitian ini di lakukan di Fakultas Ekonomi dan Bisnis Program Studi Manajemen Bisnis Telekomunikasi Informatika (MBTI). Career Development Center Telkom University melakukan survey karir pada alumni yang sudah lulus, dan dapat disimpulkan bahwa jumlah lulusan yang bekerja lebih banyak dibandingkan yang menjadi wirausaha dan juga jumlah persentase wirausaha mengalami naik turun belum stabil dan apabila dilihat dari jumlah lulusan niat mahasiswa MBTI menjadi wirausaha masih kurang, cenderung memilih bekerja.

Penjabaran diatas membuat peneliti tertarik untuk mengetahui kesenjangan implementasi kurikulum mata kuliah wajib kewirausahaan di Universitas Telkom Program Studi MBTI angkatan 2015 berdasarkan Rancangan Program Studi (RPS), maka dilihat harapan mahasiswa dan persepinya, serta diukur kompetensi berwirausaha yang dimiliki oleh mahasiswa setelah menyelesaikan proses pembelajaran kewirausahaan. 


\section{Rumusan Masalah}

Berdasarkan rumusan masalah yang sudah diuraikan, peneliti ingin mengajukan pertanyaan meliputi:

1. Seberapa besar kesenjangan antara harapan mahasiswa dengan persepsi mahasiswa terhadap pelaksanaan kurikulum kewirausahaan di program studi MBTI angkatan 2015 ?

2. Seberapa tinggi tingkat kompetensi berwirausaha dari mahasiswa program studi MBTI angkatan 2015 yang telah menyelesaikan proses pembelajaran kewirausahaan wajib?

\section{Tujuan Penelitian}

Berdasarkan pertanyaan penelitian yang ada, maka didapatkan tujuan penelitian sebagai berikut:

1. Untuk mengetahui seberapa besar kesenjangan antara harapan mahasiswa dengan persepsi mahasiswa terhadap pelaksanaan kurikulum kewirausahaan di program studi MBTI angkatan 2015.

2. Untuk mengetahui seberapa tinggi tingkat kompetensi berwirausaha dari mahasiswa MBTI angkatan 2015 yang telah menyelesaikan proses pembelajaran kewirausahaan wajib.

\section{KAJIAN PUSTAKA \\ Entrepreneurship}

Basrowi (2016:3) menjelaskan wirausaha adalah seseorang yang memperkenalkan barang dan jasa baru yang sebelumnya belum pernah ada, dengan menciptakan organisasi baru atau mengolah bahan baku baru. Saroni, (2014:32) mengemukakan bidang entrepreneur adalah bidang yang didalamnya terdapat kegiatan dan pengambilan keputusan yang memerlukan risiko dan keberanian, serta memerlukan inovasi dan improvisasi untuk dapat memberikan manfaat lebih dan dapat menumbuhkan kreativitas untuk dapat menjalankan aktivitas kewirausahaan.

Pentingnya entrepreneurship (kewirausahaan) untuk pengembangan ekonomi, penciptaan lapangan kerja dan inovasi telah meningkatkan kekhawatiran para peneliti dan pengambil keputusan pada tingkat yang berbeda untuk memahami dan menyelidiki faktor-faktor yang dapat berdampak pada tingkat aktivitas kewirausahaan (Teixeira, 2018). Sementara Farashah (2017: 880) menjelaskan bahwa literature utama entrepreneurship memfokuskan pada studi di negara-negara dengan lingkungan bisnis yang dikembangkan dan direalisasikanparadigma ekonomi neoliberal yang didorong oleh inovasi dan teknologi tinggi. Sehingga dapat disimpulkan bahwa entrepreneurship merupakan proses membuat ide dan inovasi yang memberikan nilai lebih dan menciptakan sesuatu yang baru atau berbeda.

\section{Pendidikan Kewirausahaan di Perguruan Tinggi}

Mwasalwiba (2010:25) menuliskan dalam penelitiannya bahwa ada 32\% artikel yang diteliti terkait dengan pendidikan kewirausahaan seperti mencoba memiliki tujuan yang mampu mempengaruhi sikap, perilaku, nilai, atau niat individu. Pendidikan kewirausahaan termasuk dalam kurikulum sebagai tema lintas-kurikuler yang bertujuan 
untuk menyelaraskan pendidikan dan pengajaran, dan tujuannya untuk membantu siswa memahami masyarakat secara luas dari perspektif aktor yang berbeda, untuk mengembangkan keterampilan yang diperlukan dalam kewarganegaraan aktif dan untuk meletakkan landasan bagi praktik kewirausahaan (Ruskovaara dan Pihkala 2013:207). Topik pendidikan kewirausahaan menjadi perhatian penting bagi policy makers karena telah menargetkan bahwa pengajaran kewirausahaan sebagai strategi kunci yang memungkinkan daya saing ekonomi Negara dapat maju (Tognazzo et al., 2017: 48).

\section{Pembelajaran Kewirausahaan di Perguruan Tinggi}

Mwasalwiba (2010:24), menjelaskan dalam penelitiannya mengenai aspekaspek yang ada dalam pendidikan kewirausahaan. Terdapat 5 aspek yang dibahas dalam penelitian ini, Definition and objectives of Entrepreneurship Education, Specific Objectives, Teaching Methods, Community outreach activities, dan Evaluation and impact indicators. Hal ini juga berbeda dengan penelitian yang dilakukan oleh Tang et al., (2014) yang mencoba melakukan analisis terhadap program Entrepreneurship Education (EE) di China dengan menganalisis entrepreneurship courses yang diterapkan dalam program tersebut. Pada jurnal penelitiannya, Spiteri \& Maringe (2014:65) mencoba memahami berbagai model pembelajaran yang menjadi kebutuhan belajar mahasiswa, serta trainer yang tepat untuk menyampaikan program Entrepreneurship Education (EE) tersebut. Dari 4 perguruan tinggi yang dijadikan penelitian, Spiteri \& Maringe (2014:65) menyimpulkan 3 saran model proses pembelajaran, Teaching pedadogy (metode pengajaran dosen), KTP model (mentoring dan kerja praktek) dan Worthwhile knowledge (pengetahuan yang diberikan/kurikulum).

\section{Kompetensi Wirausaha}

Basrowi (2016:29) menyatakan bahwa seseorang yang memiliki ilmu pengetahuan, keterampilan dan kualitas individu meliputi motivasi, sikap, nilai serta tingkah laku yang dibutuhkan dalam melaksanakan kegiatan ataupun pekerjaan itu disebut wirausaha sukses yang memiliki kompetensi. Pada penelitian yang dilakukan oleh Ferrandiz et al., (2018) menyatakan bahwa kurikulum yang diterapkan pada mahasiswa dapat mengembangkan entrepreneur skills dan business idea yang terdiri dari creativity and generating ideas, strategic diagnosis, market research, product development, marketing, accounting and finance, sales and tax aspects, human resources, entrepreneurial mentality, teamwork, selling skills, dan leadership. Creativity skill merupakan kreatif berpikir yang mampu menghasilkan keduanya solusi inovatif dan penggunaan yang relevan informasi untuk memahami "big picture" (Venture prise, 2018). Pada hasil penelitian Tang et al., (2014:170) negotiation skills merupakan kompetensi yang paling diharapkan oleh mahasiswa, diikuti oleh problem solving skills, marketing skills, management and leadership skills, social-networkbuilding skills, and expertise-acquisition skills. 


\section{Model SERVQUAL}

Menurut Tjiptono (2016:149) model kualitas jasa yang hingga kini banyak dijadikan acuan dalam riset pemasaran adalah model SERVQUAL (singkatan dari service quality) yang dikembangkan oleh Parasuraman, Zeithaml, dan Berry. Model SERVQUAL meliputi analisis terhadap 5 gap yang berpengaruh terhadap kualitas jasa.

\section{Gambar 1. Model Konseptual SERVQUAL}

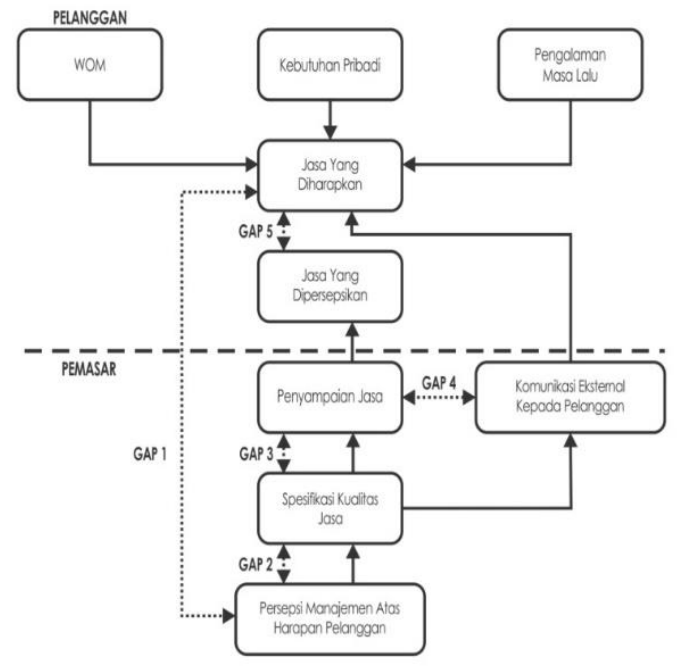

Sumber: Zeithaml et al., (1990) dalam buku Tjiptono dan Chandra, (2016:152)

Dengan kata lain, faktor utama yang mempengaruhi kualitas layanan adalah layanan yang diharapkan pelanggan (expected service) dan persepsi terhadap layanan (perceived service) (Parasuraman, et al, 1985). Menurut Spreng, MacKenzia \& Olshavsky dalam Tjiptono (2011:308) persepsi adalah suatu keyakinan yang berkaitan dengan atribut produk, tingkat atribut, atau hasil. Sedangkan harapan/ekspektasi pelanggan menurut Anderson \& Chambers, 1985 dalam Tjiptono (2011:307) mengemukakan bahwa harapan/ekspektasi adalah sesuatu yang diyakini seseorang akan didapatkannya berkaitan dengan persepsi alternatif penyedia jasa berdasarkan pemrosesannya terhadap ketersediaan sumber-sumber informasi.

\section{METODE PENELITIAN}

\section{Jenis Penelitian}

Jenis penelitian ini yaitu penelitian deskriptif dan kesenjangan (GAP). Penelitian deskriptif dilakukan untuk mendeskripsikan tanggapan mahasiswa terhadap harapan dan persepsi mengenai kurikulum Pendidikan kewirausahaan wajib serta mengukur kompetensi yang dimiliki setelah menyelesaikan mata kuliah kewirausahaan wajib. Sedangkan analisis kesenjangan digunakan untuk melihat kesenjangan antara harapan mahasiswa dengan persepsi mahasiswa terhadap pelaksanaan kurikulum kewirausahaan wajib.

\section{Tempat dan Waktu Penelitian}

Penelitian ini dilakukan di Fakultas Ekonomi dan Bisnis Program Studi MBTI. Waktu penelitian dilakukan mulai bulan November 2018 sampai Januari 2019. 


\section{Populasi dan Sampel}

Populasi adalah jumlah keseluruhan yang terdiri atas objek atau subjek yang mempunyai karakteristik dan kualitas tertentu yang di tetapkan oleh peneliti untuk diteliti kemudian ditarik kesimpulannya (Sujarweni, 2015:80).

Dalam pengambilan sampel ini menggunakan rumus Slovin, berikut ini adalah rumus slovin sebagai berikut (Sujarweni, 2015:82) :

$$
\mathrm{n}=\frac{N}{1+\left(N x e^{2}\right)}
$$

Dimana:

$\mathrm{n} \quad=$ Ukuran sampel

$\mathrm{N} \quad=$ Populasi

$\mathrm{E}=$ Prosentasi kelonggaran ketidakterikatan karena kesalahan pengambilan sampel yang masih diinginkan $(5 \%)$

Dalam menciptakan populasi $(\mathrm{N})$, dilakukan perhitungan menggunakan ratarata. Berdasarkan rumus Slovin diatas, maka ukuran sampel dalam pnelitian ini sebagai berikut:

$$
\begin{gathered}
n=\frac{543}{1+543(0,05)^{2}} \\
n=230.3 \rightarrow 231
\end{gathered}
$$

Jadi, sampel yang dibutuhkan adalah sebanyak 231 responden. Jumlah responden akan diambil dari mahasiswa Telkom University prodi MBTI angkatan 2015.

\section{Teknik Pengumpulan Data}

Untuk memperoleh data, peneliti melakukan penyebaran kuesioner kepada mahasiswa Program Studi MBTI angkatan 2015, dan mengunakan data-data internal institusi.

\section{Teknik Analisis}

Gap indikator merupakan selisih antara persepsi (kinerja) dan harapan mahasiswa pada setiap indikator dalam tiap dimensi yang digunakan. Gap indikator pada penelitian ini di hitung menggunakan rumus:

$$
G_{i}=\left(\sum P_{i}\right)-\left(\sum E_{i}\right)
$$

Sumber: Zeithaml, et al., (1990) dalam Tjiptono dan Chandra (2016:159)

Gap dimensi merupakan selisih antara persepsi (kinerja) dan harapan ekspektasi (harapan) mahasiswa pada setiap dim ensi dalam kurikulum pendidikan kewirausahaan. Gap dimensi pada penelitian ini di hitung menggunakan rumus:

$$
G_{j}=\left(\sum P_{j}\right)-\left(\sum E_{j}\right)
$$

Sumber: Zeithaml, et al., (1990) dalam Tjiptono dan Chandra (2016:159)

Gap pada SERVQUAL atau apabila disesuaikan dengan penelitian penulis menjadi gap pada kurikulum pendidikan kewirausahaan merupakan selisih antara persepsi (kinerja) 
dan harapan mahasiswa dalam keseluruhan dimensi. Gap pada kurikulum pendidikan kewirausahaan dihitung dengan rumus:

$$
G=\left(\sum P\right)-\left(\sum E\right)
$$

Sumber: Zeithaml, et al., (1990) dalam Tjiptono dan Chandra (2016:159)

(3.19)

Jika kesenjangan $(G A P)$ lebih besar dibandingkan 1, maka kualitas pelayanan dikatakan baik (Wijaya, 2018:145). Apabila disesuaikan dengan penelitian penulis maka kesenjangan $(G A P)$ yang negatif atau kurang dari 0 menunjukkan bahwa terdapat kesenjangan antara tujuan dan pelaksanaan pembelajaran kewirausahaan di program studi MBTI, dan perlu adanya perbaikan atau peningkatan performansi.

\section{HASIL PENELITIAN DAN PEMBAHASAN}

Analisis deskriptif dari variabel kompetensi untuk dimensi conceptual skills berada dalam kategori tinggi dengan perolehan persentase sebesar 77,03\%. Berikutnya variabel kompetensi untuk dimensi managerial skills berada dalam kategori tinggi dengan perolehan persentase sebesar $77,72 \%$. Kemudian analisis deskriptif dari variabel kompetensi untuk dimensi negoitation skills berada dalam kategori tinggi dengan perolehan persentase sebesar $75,78 \%$. Variabel kompetensi untuk dimensi creativity skills berada dalam kategori tinggi dengan perolehan persentase sebesar 76,9\%. Kemudian dari variabel kompetensi untuk dimensi problem solving skills berada dalam kategori tinggi dengan perolehan persentase sebesar 78,35\%. Berikutnya dari variabel kompetensi untuk dimensi teamwork skills berada dalam kategori tinggi dengan perolehan persentase sebesar 78,37\%. Analisa deskriptif dari variabel kompetensi untuk dimensi terakhir yaitu leadership skills berada dalam kategori tinggi dengan perolehan persentase sebesar 78,79\%.

Indikator yang memiliki gap paling besar dan paling negative adalah indikator item ke 5 pada dimensi rencana pembelajaran mata kuliah CTIB yaitu sebesar -0,749. Indikator tersebut mengenai pernyataan mampu melakukan negoisasi dalam memperoleh pendanaan eksternal bagi komersialisasi. Hal tersebut menunjukkan bahwa melakukan negoisasi dalam memperoleh pendanaan eksternal bagi komersialisasi yang diajarkan selama perkuliahan belum sesuai dengan harapan.

Nilai harapan dimensi rencana pembelajaran mata kuliah CTIB yaitu sebesar 5,877, sedangkan untuk nilai persepsi sebesar 5,387. Sehingga diperoleh gap sebesar 0,499 . Selisih yang dihasilkan negatif, artinya terjadi kesenjangan antara harapan dan persepsi pada dimensi rencana pembelajaran mata kuliah CTIB dimana persepsi atau kinerja yang dirasakan selama perkuliahan masih kurang dibandingkan dengan apa yang di harapkan mahasiswa. Kemudian nilai harapan dimensi rencana pembelajaran mata kuliah kewirausahaan sebesar 5,997, sedangkan untuk nilai persepsi sebesar 5,626, sehingga diperoleh gap sebesar -0,371. Selisih yang dihasilkan negatif, artinya terjadi kesenjangan antara harapan dan persepsi pada dimensi rencana pembelajaran mata kuliah kewirausahaan dimana persepsi atau kinerja yang dirasakan selama perkuliahan masih kurang dibandingkan dengan apa yang di harapkan mahasiswa. Terakhir nilai harapan dimensi rencana pembelajaran mata kuliah proyek kewirausahaan sebesar 5,906, sedangkan nilai persepsi sebesar 5,667, sehingga 
diperoleh gap sebesar -0,239. Selisih yang dihasilkan negatif, artinya terjadi kesenjangan antara harapan dan persepsi pada dimensi rencana pembelajaran mata kuliah proyek kewirausahaan dimana persepsi atau kinerja yang dirasakan selama perkuliahan masih kurang dibandingkan dengan apa yang di harapkan mahasiswa.

Penelitian yang dilakukan oleh Agustina, (2011:70) ada beberapa solusi yang bisa dilakukan institusi dalam menangani kesenjangan atau masalah dalam program kewirausahaan, salah satunya dengan membuat incubator bisnis. Keberadaan inkubator bisnis diharapkan dapat mengatasi berbagai permasalahan di perguruan tinggi diatas dengan :

a. Aktivitas riset pasar.

b. Mengatasi masalah kurangnya kemampuan manajerial (managerial skills).

c. Kerjasama antar lembaga.

d. Pembentukan unit bisnis.

e. Pengembangan.

Dapat disimpulkan bahwa dengan adanya inkubator bisnis bisa membantu mengurangi masalah yang menjadi gap pada setiap indikator. Berdasarkan dimensi rencana pembelajaran mata kuliah CTIB, hanya satu indikator yang dapat diatasi dengan inkubator yaitu mampu melakukan negoisasi dalam memperoleh pendanaan eksternal bagi komersialisasi, hal ini bisa diatasi dengan point "kerjasama antar lembaga".

Dimensi rencana pembelajaran mata kuliah kewirausahaan, terdapat 4 indikator yang dapat diatasi dengan inkubator. Inkubator mengatasi masalah kurangnya kemampuan manajerial (managerial skills), dapat mengatasi managerial skills yang terdapat di mata kuliah kewirausahaan yaitu, mendeskripsikan hasil tes pasar, menghubungkan aspek-aspek manajemen dalam perencanaan bisnis dan analisis ide bisnis. Selanjutnya inkubator kerjasama antar lembaga, mengatasi indikator mampu melakukan negoisasi di depan investor.

Dimensi rencana pembelajaran mata kuliah proyek kewirausahaan, terdapat 2 indikator yang dapat diatasi dengan inkubator. Inkubator mengatasi masalah kurangnya kemampuan manajerial (managerial skills), dapat mengatasi managerial skills yang terdapat di mata kuliah proyek kewirausahaan yaitu mampu memahami sambil mempraktikkan dunia usaha nyata dalam mengelola aspek-aspek manajemen. Kemudian indikator mampu melakukan negoisasi dengan supplier, diatasi dengan inkubator kerjasama antar lembaga.

\section{KESIMPULAN DAN SARAN \\ Kesimpulan}

Berdasarkan hasil analisa gap, terdapat gap atau kesenjangan antara harapan dan persepsi mahasiswa terhadap kurikulum pendidikan kewirausahaan sebesar $-0,370$, hal ini menunjukan bahwa harapan mahasiswa terhadap kurikulum pendidikan kewirausahaan lebih tinggi dibandingkan kinerja yang sudah dirasakan selama perkuliahan berlangsung. Terdapat 9 indikator pernyataan yang gapnya diatas $-0,35$, yang menunjukan perlunya perhatian yang lebih tinggi. Dimensi rencana pembelajaran mata kuliah CTIB dan kewirausahaan merupakan dimensi yang perlu diberikan perhatian yang lebih tinggi karena memiliki gap diatas $-0,35$. Berdasarkan hasil analisis 
deskriptif, kompetensi wirausaha mahasiswa setelah mengikuti pembelajaran pendidikan kewirausahaan berada dalam kategori sedang cenderung tinggi, yaitu sebesar 78\%. Menunjukan bahwa mahasiswa tidak sepenuhnya setuju memiliki kompetensi tersebut.

\section{Saran}

\section{Untuk Perguruan Tinggi}

Beberapa saran yang diberikan penulis kepada program studi MBTI adalah sebagai berikut:

a. Berdasarkan hasil evaluasi ketiga mata kuliah kewirausahaan wajib, mata kuliah yang mendapatkan prioritas untuk dilakukan evaluasi lebih lanjut adalah mata kuliah CTIB, karena semua indikator pernyataan memiliki gap yang tinggi. Berikut saran yang perlu dilakukan yaitu:

1. Melakukan pencarian fakta dengan cara wawancara terpisah antara mahasiswa, dosen dan tim kurikulum.

2. Dosen, mahasiswa dan tim kurikulum di pertemukan dalam satu diskusi kelompok terarah $(F G D)$ agar menemukan kendala yang sebenarnya terjadi di mata kuliah CTIB.

b. Layanan inkubator Fakultas Ekonomi dan Bisnis yang disarankan untuk diimplementasikan menurut Ristekdikti (2017), yaitu:

1. Infrastruktur bisnis. Fasilitas fisik yang wajib disediakan inkubator untuk penunjang bisnis diantaranya ruang usaha tenant, ruang kantor, ruang rapat atau pertemuan bisnis, sarana telekomunikasi, akses internet dan peralatan perkantoran. Berdasarkan hal tersebut fasilitas diatas diperlukan untuk menopang adanya infastruktur bisnis.

2. Pendamping Bisnis (Business Coaching). Layanan-layanan pengembangan bisnis bagi tenant-nya antaranya, pengembangan bisnis, pengembangan teknologi dan proses produksi, konsultasi bisnis, pembuatan business plan, pendirian legalitas usaha, standarisasi produk, sertifikasi produk, pendaftaran HKI, penyediaan mentoring bisnis, pengujian produk, promosi produk, riset pasar dan pelatihan bisnis. Beberapa layanan yang belum tersedia dan bisa diterapkan di program studi MBTI pengembangan teknologi dan proses produksi, konsultasi bisnis, penyediaan mentoring bisnis dengan pengusaha sukses, pengujian produk, riset pasar dan pelatihan bisnis.

3. Akses Pemodalan Bisnis (Fund Raising). Inkubator membantu untuk pendampingan dalam akses kredit modal usaha atau mencairkan angle investor melalui, akses modal ke Lembaga Perbankan dan Non Bank, serta akses modal ke Lembaga Pemerintahan.

4. Jejaring dan Kolaborasi (Networkings and Collaboration). Memberikan sarana untuk membangun jejaring bisnis dan kolaborasi bisnis, diantaranya kerjasama dengan Lembaga Penelitian dan Pengembangan atau Lembaga Alih Teknologi, kemitraan bisnis dengan pengusaha, kegiatan dengan inkubator dan forum inkubator nasional dan internasional. 
Contohnya melakukan kolaborasi secara internal dan eksternal, yaitu:

- Internal dapat melakukan kerjasama dengan fakultas lain.

- Eksternal dapat berkolaborasi dengan pihak government dan industri. Jika dengan government, mahasiswa dapat berkaitan dengan kebijakan, perizinan dan program pemerintah. Jika dengan industri, bisnis yang dijalankan mahasiswa, industri tersebut yang akan menjadi pasarnya sehingga bisnis akan menjadi lebih pasti.

c. Rencana Pembelajaran Studi (RPS) dari ketiga mata kuliah kewirausahaan wajib perlu dikaji ulang, karena penggunaan kalimat untuk merumuskan tujuan yang akan dicapai memiliki makna arti ganda.

\section{Untuk Peneliti Selanjutnya}

Beberapa saran yang diberikan penulis kepada penelitian selanjutnya adalah:

a. Melakukan penelitian longitudinal studi.

b. Program pendukung lebih baik dilakukan dengan cara kualitatif dengan mewawancari beberapa mahasiswa dan dosen untuk memahami fenomena dengan lebih baik.

\section{DAFTAR PUSTAKA}

Basrowi. 2016. Kewirausahaan Untuk Perguruan Tinggi . Bogor: Ghalia Indonesia.

Candra, T. 2017. Menatap Indonesia Cerah Jauh dari Pengangguran. Retrieved September 28, 2018, from Kompasiana: https://www.kompasiana.com/taufiq123/59ad6514b881b606b84b9de2/menatapindonesia-cerah-jauh-dari-pengangguran

Farashah, A. D. 2013. The process of impact of entrepreneurship education and perception and intention Study of educational system of Iran. Education + Training, Vol. 55 Iss 8/9 pp.868-885.

Ferrandiz, J., Fidel, P., \& Conchado, A. 2018. Promoting Entrepreneurial Intention Through Higher Education In Entrepreneurship And The Participation Of Students In An Entrepreneurship Ecosystem. International Journal of Innovation Science. 1-22.

Kuswara, H. 2012. Strategi Perguruan Tinggi Mewujudkan Entrepreneurial Campus. Retrieved September 12, 2018, from Kementerian Riset, Teknologi, Dan Pendidikan Tinggi: https://ristekdikti.go.id/kolom-opini/strategi-perguruantinggi-mewujudkan-entrepreneurial-campus/

Mwasalwiba, E. S. 2010. Entrepreneurship education: a review of its objectives, teaching methods, and impact indicators. Education + Training, Vol. 52(Iss 1), pp. 20-47.

Purwana, D., \& Wibowo, A. 2017. Pendidikan Kewirausahaan di Perguruan Tinggi. Pustaka Pelajar.

Ruskovaara, E., \& Pihkala, T. 2013. Teachers implementing entrepreneurship education: classroom practices. Education + Training, Vol. 55 Iss 2 pp. 204-216.

Saroni, M. 2012. Mendidik \& Melatih Entrepreneur Muda: Membuka Kesadaran Atas Pentingnya Kewirausahaan bagi Anak Didik. Jogjakarta: AR-RUZZ MEDIA.

Spiteri, S., \& Maringe, F. 2014. EU entrepreneurial learning: Journal of Enterprising Communities: People and Places in the Global, Vol. 8 Iss 1 pp. 51-70. 
Sujarweni, W. V. 2015. Metodologi Penelitian Bisnis \& Ekonomi. Yogyakarta: PT. Pustaka Baru.

Tang, M., Chen, X., Li, Q., \& Lu, Y. 2014. Does Chinese university entrepreneurship education fit students' needs? . Vol. 6 Iss 2 pp. 163-178.

Teixeira, S. J., Casteleiro, C. M., Rodrigues, R., \& Guerra, M. 2017. ENTREPRENEURIAL INTENTIONS AND ENTREPRENEURSHIP. International Journal of Innovation Science, 1-16.

Tognazzo, A., Gianecchini, M., \& Gubitta, P. 2017. EDUCATIONAL CONTEXT AND ENTREPRENEURIAL INTENTIONS OF UNIVERSITY STUDENTS: AN ITALIAN STUDY. Entrepreneurship Education: New Perspectives on Entrepreneurship Education, Volume 7, 47-74.

Tjiptono, F., \& Chandra, G. 2011. Service, Quality \& Satisfaction (3 ed.). Yogyakarta: ANDI.

Tjiptono, F., \& Chandra, G. 2016. Service, Quality dan Satisfaction (4 ed.). Yogyakarta: C.V ANDI OFFSET.

Trading Economic. 2018. Tingkat Pengangguran - Daftar Negara - Asia. Retrieved Agustus 22, 2018, from Trading Economics: https://id.tradingeconomics.com/country-list/unemployment-rate?continent=asia

Wijaya, T. 2018. Manajemen Kualitas Jasa. Jakarta: Indeks 